\title{
Correction to: Effectiveness and safety of opicapone in Parkinson's disease patients with motor fluctuations: the OPTIPARK open-label study
}

\author{
Heinz Reichmann ${ }^{1}$, Andrew Lees ${ }^{2}$, José-Francisco Rocha ${ }^{3}$, Diogo Magalhães ${ }^{3,5}$, Patrício Soares-da-Silva ${ }^{4,5,6^{*}}$ and the \\ OPTIPARK investigators
}

\section{Correction to: Transl Neurodegener (2020) 9:9 \\ https://doi.org/10.1186/s40035-020-00187-1}

In this published article [1], the efficacy data for the below outcomes were unfortunately not supplied based on the Full Analysis Set (FAS) at 3 and/or 6 months for specific outcomes under the statistical analysis plan (SAP). The SAP specified that the efficacy data should be based overall on the FAS at 3 months for the primary (with last observation carried forward, LOCF) and secondary (no LOCF) efficacy endpoints and 6 months for UK only (no LOCF). The amendments do not change the conclusions of the paper, and the corrected data are given below.

Clinician and patient global impressions of change

Correction to CGI-C 6-month data (UK patients only)

[ ... ] For those UK patients $(n=95)$ who were also assessed at 6 months, $85.3 \%$ were judged as improved since commencing treatment $(8.4 \%$ very much improved and $49.5 \%$ much improved) while $8.4 \%$ were judged as showing 'no change' and $6.4 \%$ as having worsened. [ ... ]

Correction to Fig. 2b

Rating scale outcomes

Correction to UPDRS analyses (Table 2)

The original article can be found online at https://doi.org/10.1186/s40035 020-00187-1.

* Correspondence: psoares.silva@bial.com

${ }^{4}$ Research and Development Department, BIAL - Portela \& CA S. A, da Siderurgia Nacional, 4745-457 S Mamede do Coronado, Portugal

${ }^{5}$ Department of Pharmacology and Therapeutics, Faculty of Medicine, University Porto, Porto, Portugal

Full list of author information is available at the end of the article
$\mathrm{N}$ numbers for UPDRS Part II were 475 at baseline and 389 at 3 months (Visit 4); results of the change from baseline analysis remain unchanged. $\mathrm{N}$ numbers for UPDRS Part III were 476 at baseline and 391 at 3 months; results of the change from baseline analyses remain unchanged.

\section{Correction to Table 2.}

\section{Levodopa dosing}

\section{Correction to levodopa dosing}

After 3 months of treatment with opicapone, most patients remained on the same total daily levodopa frequency $(77.1 \%$ had no change, $10.4 \%$ had an increase and $12.5 \%$ had a decrease in dosing frequency), resulting in an overall mean change of approximately $-10 \mathrm{mg} /$ day. [...].

\section{Discussion}

\section{Correction to discussion}

[ ... ] These judgements made by the investigators were corroborated by the patients themselves.

with $48.1 \%$ patients reporting they were much or very much improved after 3 months treatment with opicapone $50 \mathrm{mg}$. [...] 


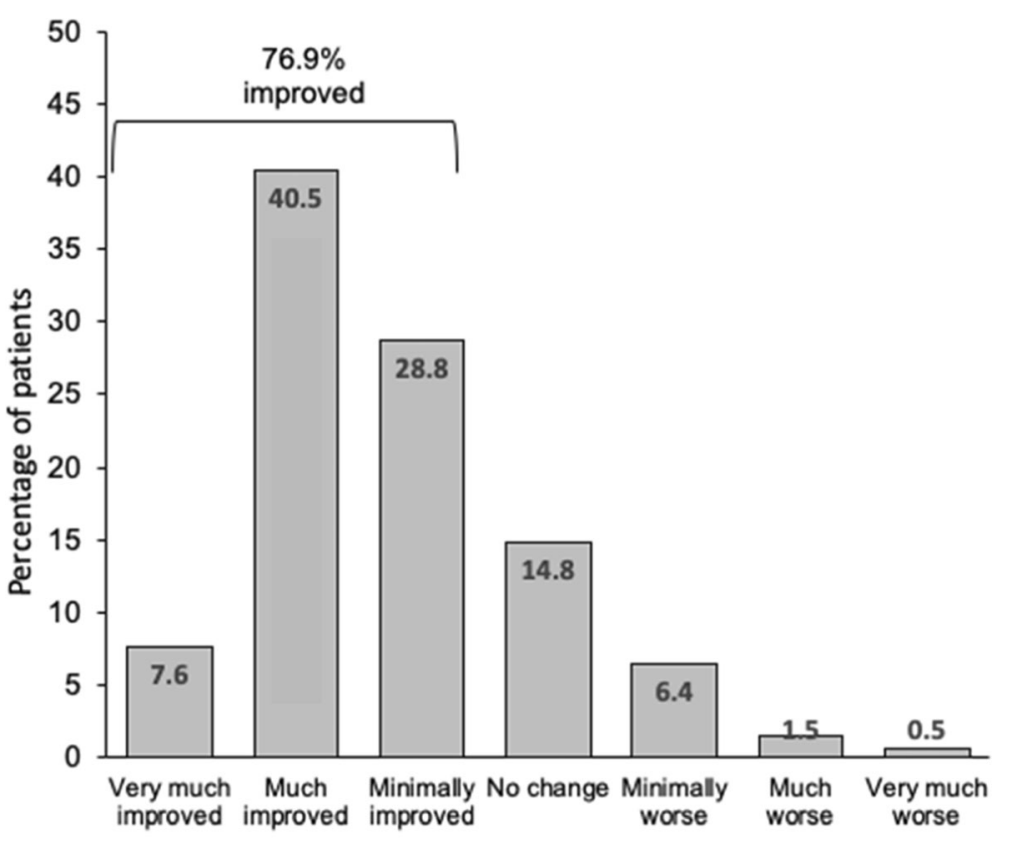

Patient's Global Impression of Change ( $n=393)$

Fig. 2 Global Impression of Change following 3 months treatment with opicapone $50 \mathrm{mg}$ (a) investigator rated (CGI-C, $n=477$, LOCF); (b) selfrated by the patient $(\mathrm{PGI}-\mathrm{C}, n=393)$

Table 2 Rating scale assessments

\begin{tabular}{ll}
\hline Rating scale & \\
\hline$[\ldots]$ & \\
UPDRS Part II (ADL during OFF); mean \pm SD & $17.1 \pm 7.0$ \\
$\quad$ Baseline $(n=475)$ & $13.9 \pm 6.8$ \\
3 months $(n=389)$ & $-3.0 \pm 4.6$ \\
Change from baseline $(n=389)$ & $<0.0001$ \\
$P$ value vs. baseline & \\
UPDRS Part III (motor scores during ON); mean \pm SD & $26.5 \pm 12.1$ \\
Baseline ( $n=476)$ & $21.5 \pm 11.0$ \\
3 months ( $n=391)$ & $-4.6 \pm 8.1$ \\
Change from baseline $(n=391)$ & $<0.0001$ \\
$P$ value vs. baseline & \\
{$[\ldots]$} & \\
\hline
\end{tabular}

NMSS Non-motor symptom scale, UPDRS Unified Parkinson's Disease Rating Scale, $P D Q-8$ Parkinson's Disease Questionnaire

\section{Supplementary material}

Correction to Supplementary Table 2

Results of the change from baseline in perceptual problems/hallucinations was updated to $0.0 \pm 2.01$. Results from all other analyses remain unchanged.

Supplementary Table 2 Change from baseline in NMSS domains

\begin{tabular}{ll}
\hline NMSS domain & Mean \pm SD \\
\hline$[\ldots]$ & \\
Perceptual problems/hallucinations & \\
$\quad$ Baseline & $0.8 \pm 2.45$ \\
Change from baseline ( $p$ value) & $0.0 \pm 2.01 \quad(p=0.7437)$
\end{tabular}

$[\ldots]$ 


\section{Author details}

'Department of Neurology, University of Dresden, Dresden, Germany.

${ }^{2}$ University College London, Reta Lila Weston Institute, London, UK. ${ }^{3}$ Global Parkinson's Disease Department, BIAL - Portela \& CA S.A, Coronado, Portugal.

${ }^{4}$ Research and Development Department, BIAL - Portela \& CA S. A, da Siderurgia Nacional, 4745-457 S Mamede do Coronado, Portugal.

${ }^{5}$ Department of Pharmacology and Therapeutics, Faculty of Medicine, University Porto, Porto, Portugal. ${ }^{6}$ MedlnUP, Center for Drug Discovery and Innovative Medicines, University Porto, Porto, Portugal.

\section{Published online: 28 April 2020}

\section{Reference}

1. Reichmann H, Lees A, Rocha JF, Magalhães D, Soares-da-Silva P, OPTIPARK investigators. Effectiveness and safety of opicapone in Parkinson's disease patients with motor fluctuations: the OPTIPARK open-label study. Transl Neurodegener. 2020;9:9. https://doi.org/10.1186/s40035-020-00187-1. 